\title{
Distal biceps tendon injection
}

\section{Jacqueline van der Vis ${ }^{1}$, Stein J. Janssen ${ }^{2}$, Ronald L.A.W. Bleys ${ }^{3}$, Denise Eygendaal ${ }^{2,4}$, Michel P.J. van den Bekerom $^{1,5}$; on behalf of Elbow Study Collaborative}

${ }^{1}$ Department of Orthopedic Surgery, OLVG, Amsterdam, The Netherlands

${ }^{2}$ Department of Orthopedic Surgery, Academic Medical Center, Amsterdam, The Netherlands

${ }^{3}$ Department of Anatomy, University Medical Center Utrecht, Utrecht, The Netherlands

${ }^{4}$ Department of Orthopedic Surgery, Amphia Ziekenhuis, Breda, The Netherlands

${ }^{5}$ Department of Human Movement Sciences, Vrije Universiteit Amsterdam, Amsterdam Movement Sciences, Amsterdam, The Netherlands

Background: Injection therapy around the distal biceps tendon insertion is challenging. This therapy may be indicated in patients with a partial distal biceps tendon tear, bicipitoradial bursitis and tendinopathy. The primary goal of this study was to determine the accuracy of manually performed injections without ultrasound guidance around the biceps tendon.

Methods: Seven upper limb specialists, two general orthopedic specialists, and three orthopedic surgical residents manually injected a cadaver elbow with acrylic dye using an anterior and a lateral infiltration approach. After infiltration the cadaveric elbows were dissected to determine the location of the acrylic dye.

Results: In total, $79 \%$ of the injections were localized near the biceps tendon. Of these injections, $20 \%$ were localized on the radius near the bicipitoradial bursa. In total, $53 \%$ of the performed infiltrations were injected by anterior and $47 \%$ by lateral approaches. Of the injections near the distal biceps (79\%), $47 \%$ were injected by an anterior and $53 \%$ by a lateral approach. Of the injections on the radius (20\%), 33\% were injected by anterior and $67 \%$ by lateral approach. Of the inaccurate injections (21\%), $75 \%$ were injected anterior and $25 \%$ lateral. Conclusions: Manual infiltration without ultrasound guidance for distal biceps pathology lacks accuracy. We therefore recommend ultrasound guidance for more accurate infiltration.

Keywords: Elbow; Partial biceps tendon tear; Bicipitoradial bursitis; Biceps tendinopathy; Injection therapy

\section{INTRODUCTION}

Injection therapy around the distal biceps tendon can be performed in patients with a partial biceps tendon tear, bicipitoradial bursitis or distal biceps tendinopathy. Injection therapy with platelet-rich plasma or glucocorticoids around the distal biceps tendon and in the bicipitoradial bursa is challenging because of the lack of clearly palpable landmarks; complex distal biceps anatomy; and proximity of the brachial artery, median nerve, and posterior interosseous nerve [1-7]. The bicipitoradial bursa is located between the distal biceps tendon and the anterior part of the proximal radius. The bicipitoradial bursa surrounds the biceps tendon in supination. In pronation, the radial tuberosity compresses the bicipitoradial bursa between the biceps tendon and the radial cortex [5-9].

There are different injection techniques with different ap-

Received: January 1, $2021 \quad$ Revised: March 2, 2021

Accepted: March 7, 2021

Correspondence to: Jacqueline van der Vis

Department of Orthopedic Surgery, OLVG, Oosterpark 9, 1091 AC Amsterdam, The Netherlands

Tel: +31-20-5999111, E-mail: jvandervis19@gmail.com, ORCID: https://orcid.org/0000-0001-9727-6094

Financial support: None.

Conflict of interest: None.

Copyright@ 2021 Korean Shoulder and Elbow Society.

This is an Open Access article distributed under the terms of the Creative Commons Attribution Non-Commercial License (http://creativecommons.org/licenses/by-nc/4.0/) which permits unrestricted non-commercial use, distribution, and reproduction in any medium, provided the original work is properly cited. 
proaches available for infiltration around the biceps tendon [1]. Some perform the injection manually without ultrasound guidance; others use ultrasound guidance to determine the location of the tip of the needle. The preferred location of injection is in the bicipitoradial bursa. Establishing accuracy of manually injections would improve the clinical results of injection therapy.

The primary aim of this study was to determine the accuracy of manually performed injections of the biceps tendon without radiological guidance by upper extremity surgeons. We hypothesized that manually performed injections are inaccurate and that the majority of injections ( $>50 \%$ ) would not be located in the bicipitoradial bursa or near the biceps tendon.

\section{METHODS}

This prospective study was performed during an arthroscopy and arthroplasty cadaveric course of the elbow at the University Medical Centre in Utrecht, The Netherlands. No Institutional Review Board approval is needed for cadaveric studies performed at our institution. These specimens were derived from bodies that entered the Department of Anatomy through a donation program. Written consent was obtained from these persons during life that allowed for the use of their entire bodies for educational and research purposes.

\section{Participants}

Twenty orthopedic surgeons and residents in their final year of residency attended this course that used 10 cadaveric elbows. For study purposes, the most experienced attendants of the pairs (surgeon or resident) were invited to perform two infiltrations (anterior and lateral technique) and thereby participate in this study. Twelve participants performed the infiltrations divided over these ten cadaveric elbows: seven participants performed infiltrations using both techniques; one participant only performed an anterior infiltration due to miscommunication; and four participants performed the infiltration together (in turn), one using the lateral technique and the other using the anterior technique. Seven participants were upper extremity surgeons (mean experience, 3.1 years; range, 1-10 years), two were general orthopedic surgeons ( 7 and 21 years of experience), and three were orthopedic surgery residents (in their final year of training).

Fresh-frozen human cadaveric elbow specimens were derived from bodies that had entered the Department of Anatomy of the University Medical Centre through a donation program. Written informed consent that allowed for the use of their entire bodies for educational and research purposes was obtained from these persons during their lives. None of the specimens showed signs of previous trauma or surgery affecting the elbow. The cadaveric arms were attached to a metal construction, making rotation of the arm around its axis and pronation, supination, flexion and extension of the elbow possible.

\section{Description of Infiltration Technique}

Each participant was asked to manually infiltrate the distal biceps tendon through an anterior and lateral infiltration technique using acrylic dye after instructions by one of the researchers. For the anterior approach the elbow was slightly flexed $\left( \pm 50^{\circ}-90^{\circ}\right)$, the forearm fully supinated, and the biceps tendon was localized through palpation. Then the needle was placed in the middle of the cubital fossa towards the radial tuberosity and the dye was injected. For the lateral approach the elbow was positioned in the same manner as the anterior approach. After localization of the biceps tendon, the needle was placed laterally on the elbow, radial to ulnar, with the needle passing beneath the distal biceps tendon towards the radial tuberosity. The dye was then injected. All participants received two disposable $10-\mathrm{mL}$ syringes with $23-\mathrm{G}$ needles. One syringe was filled with $2 \mathrm{~mL}$ of green acrylic dye; the other syringe was filled with $2 \mathrm{~mL}$ of red acrylic dye. The syringe with the red acrylic dye was used for the anterior infiltration technique; the syringe with the green acrylic dye was used for the lateral infiltration technique.

\section{Outcome Measures and Explanatory Variables}

The amount and location of injected dye was assessed. After the infiltrations, the elbows were dissected in order to determine whether the dye was given in or near the bicipitoradial bursa and the biceps tendon. The presence and the amount of acrylic dye were assessed and reported. The amount of acrylic dye was classified as "none," "a little" or "a lot." The location of the acrylic dye was reported as "in or near the bicipitoradial bursa" or "in or near the biceps tendon." After 5 to 10 minutes the participants were asked to dissect the elbow and locate the dye. Assessment of location was performed by both participants by consensus.

All participants were asked to complete questionnaires concerning their subspecialty, years of experience as an orthopedic surgeon and/or an upper extremity surgeon, and overall experience infiltrating the biceps tendon.

\section{RESULTS}

Each participant performed one perforation per infiltration and all injected $2 \mathrm{~mL}$ of acrylic dye in both techniques.

A total of 19 injections (10 [53\%] using the anterior infiltration technique and 9 [47\%] using the lateral infiltration technique) 
were performed in 10 cadaveric elbows. Of the 19 performed infiltrations, 15 injections (79\%) were located during dissection in or near the biceps tendon. The dye was not located near the biceps tendon in the remaining four injections (21\%). Of these four injections, three were anteriorly injected (75\%) and one was laterally injected (25\%). Three out of the 15 injections (20\%) were located (totally or partially) on the radius near the bicipitoradial bursa. Of these injections, one was given anterior (33\%) and two lateral (67\%). The remaining 12 injections (80\%) were located (totally or partially) in or near the biceps tendon. We found "a lot" of dye in 13 (87\%) of these injections. We found "a little" dye in the other two (13\%), one of which was injected anteriorly (50\%) and one laterally (50\%) (Tables 1 and 2).

\section{DISCUSSION}

We hypothesized that manually performed injections of the biceps tendon without ultrasound guidance would be inaccurate and that the majority of the injections would not be located in the bicipitoradial bursa or near the biceps tendon. The most important finding of this study was that manually performed injections of the biceps tendon lack accuracy. Only three of the nineteen injections were located (totally or partially) near the bicipitoradial bursa.

Our study had some limitations. First, infiltration around the distal biceps tendon and in the bicipitoradial bursa is challenging because of the lack of clearly palpable anatomical landmarks. Location of these anatomical landmarks is even more difficult in cadaveric arms. When infiltrating a living patient, the patient can locate the pain. This may facilitate accurate infiltration. The bio-

Table 2. Results of infiltration

\begin{tabular}{lr}
\hline Variable & Number $(\%)$ \\
\hline Infiltration technique $(\mathrm{n}=19)$ & $10(53)$ \\
$\quad$ Anterior & $9(47)$ \\
Lateral & \\
In or near biceps tendon $(\mathrm{n}=19)$ & $4(21)$ \\
$\quad$ No & $15(79)$ \\
$\quad$ Yes & \\
Infiltration technique missed injections $(\mathrm{n}=4)$ & $3(75)$ \\
$\quad$ Anterior & $1(25)$ \\
$\quad$ Lateral & \\
On the radius or near the bicipitoradial bursa $(\mathrm{n}=15)$ & $12(80)$ \\
$\quad$ No & $3(20)$ \\
Yes & \\
Infiltration technique hit injections $(\mathrm{n}=3)$ & $1(33)$ \\
$\quad$ Anterior & $2(67)$ \\
Lateral & \\
Amount of dye $(\mathrm{n}=15)$ & $13(87)$ \\
A lot & $2(13)$ \\
A little &
\end{tabular}

Table 1. Baseline characteristics and results of infiltration

\begin{tabular}{|c|c|c|c|c|c|c|}
\hline Participant no. & Cadaver no. & Infiltration technique & Dye color & $\begin{array}{l}\text { Dye in or near } \\
\text { the biceps tendon }\end{array}$ & $\begin{array}{c}\text { Dye in or near } \\
\text { bicipitoradial bursa }\end{array}$ & Amount of dye \\
\hline 1 & 1 & Anterior & Red & - & - & - \\
\hline 2 & 1 & Lateral & Green & $\bigcirc$ & - & A lot \\
\hline 3 & 2 & Anterior & Red & $\bigcirc$ & $\bigcirc$ & A lot \\
\hline 4 & 2 & Lateral & Green & $\bigcirc$ & $\bigcirc$ & A little \\
\hline \multirow[t]{2}{*}{5} & 3 & Anterior & Red & $\bigcirc$ & - & A little \\
\hline & & Lateral & Green & & - & A lot \\
\hline \multirow[t]{2}{*}{6} & 4 & Anterior & Red & 0 & - & A lot \\
\hline & & Lateral & Green & - & - & - \\
\hline \multirow[t]{2}{*}{7} & 5 & Anterior & Red & $\bigcirc$ & - & A lot \\
\hline & & Lateral & Green & & - & A lot \\
\hline \multirow[t]{2}{*}{8} & 6 & Anterior & Red & - & - & - \\
\hline & & Lateral & Green & $\bigcirc$ & - & A lot \\
\hline \multirow[t]{2}{*}{9} & 7 & Anterior & Red & 0 & - & A lot \\
\hline & & Lateral & Green & $\bigcirc$ & - & A lot \\
\hline \multirow[t]{2}{*}{10} & 8 & Anterior & Red & - & - & - \\
\hline & & Lateral & Green & $\bigcirc$ & $\bigcirc$ & A lot \\
\hline \multirow[t]{2}{*}{11} & 9 & Anterior & Red & $\bigcirc$ & 0 & A lot \\
\hline & & Lateral & Green & $\bigcirc$ & & A lot \\
\hline 12 & 10 & Anterior & Red & 0 & - & A lot \\
\hline
\end{tabular}


mechanical properties of tissue are different in cadavers as compared to living subjects. However, the fresh frozen cadavers used in this study accurately resembled living tissue [10]. Second, during the study we mainly focused on the location of the dye. We did not assess the structures passed by the needle; therefore, the needle may have caused neurovascular injuries. Leaving the needle in place and dissecting the pathway might have helped assess this. Third, the acrylic dye had to set for 5-10 minutes, but some participants started their dissection too early due to other course activities. This may explain the smaller amounts of dye found. Fourth, bias may have been introduced by having the participants dissect and assess their own injected elbows. Fifth, the sample size of the cadavers and participants in our study was small and did not allow for stratification based on experience or skill. However, a larger sample size would probably not change our conclusions. Further, none of the participants had previously performed an infiltration of the distal biceps tendon without radiological guidance. Most colleagues ask a radiologist to perform these infiltrations using ultrasound guidance in daily practice.

Previous studies have shown that infiltration in the bicipitoradial bursa with ultrasound guidance is difficult. There are several viable options described for infiltration with ultrasound guidance. Sellon et al. [1] found a high success rate for sonographically guided peritendinous and intratendinous infiltration of the distal biceps tendon through multiple approaches. All of their peritendinous injections were successful, and $94 \%$ of their intratendinous injections were successful. Mautner et al. [4] demonstrated with their case study that an ultrasound-guided, posterior, in-plane approach for distal biceps tendon infiltration was safe and effective. Chang et al. [11] demonstrated that an ultrasound-guided infiltration of the bicipitoradial bursa for bicipitoradial bursitis was safe and successful. In comparison, for the infiltration of the shoulder girdle, Aly et al. [12] found an improved accuracy for ultrasound-guided injections compared to landmark-guided injections.

In daily practice we recommend infiltration of the bicipitoradial bursa using ultrasound guidance. This technique allows for a more accurate injection and more optimal treatment of a partial biceps tendon tear, bicipitoradial bursitis or tendinopathy. Further studies on infiltrations of the distal biceps tendon in living human subjects are needed. These should focus on the clinical efficacy and accuracy of ultrasound-guided and manually performed injections. Infiltration of the bicipitoradial bursa without ultrasound guidance lacks accuracy. For more accurate treatment of a partial biceps tendon tear, bicipitoradial bursitis or tendinopathy, we recommend infiltration of the bicipitoradial bursa using ultrasound guidance. Further studies on infiltrations of the distal biceps tendon in human subjects, particularly a study that directly compares manual versus ultrasound-guided infiltrations, will be useful.

\section{ACKNOWLEDGMENTS}

Elbow Study Collaborative: Marc Wagener, Lex Boerboom, Carina Gerritsma, Bertram The, Roger van Riet, Jaap Willems.

\section{ORCID}

Jacqueline van der Vis https://orcid.org/0000-0001-9727-6094

Stein J. Janssen https://orcid.org/0000-0003-3939-7765

Ronald L.A.W. Bleys

https://orcid.org/0000-0002-5408-038X

Denise Eygendaal

https://orcid.org/0000-0003-3922-2949

Michel P.J. van den Bekerom https://orcid.org/0000-0002-1184-0529

\section{REFERENCES}

1. Sellon JL, Wempe MK, Smith J. Sonographically guided distal biceps tendon injections: techniques and validation. J Ultrasound Med 2014;33:1461-74.

2. Sanli I, Morgan B, van Tilborg F, Funk L, Gosens T. Single injection of platelet-rich plasma (PRP) for the treatment of refractory distal biceps tendonitis: long-term results of a prospective multicenter cohort study. Knee Surg Sports Traumatol Arthrosc 2016;24:2308-12.

3. Barker SL, Bell SN, Connell D, Coghlan JA. Ultrasound-guided platelet-rich plasma injection for distal biceps tendinopathy. Shoulder Elbow 2015;7:110-4

4. Mautner K, Stafford CD 2nd, Nguyen P. Ultrasound-guided distal bicep tendon injection using a posterior approach. PM R 2015;7:1007-10.

5. Bain GI, Johnson LJ, Turner PC. Treatment of partial distal biceps tendon tears. Sports Med Arthrosc Rev 2008;16:154-61.

6. Chew ML, Giuffrè BM. Disorders of the distal biceps brachii tendon. Radiographics 2005;25:1227-37.

7. Draghi F, Gregoli B, Sileo C. Sonography of the bicipitoradial bursa: a short pictorial essay. J Ultrasound 2012;15:39-41.

8. van den Bekerom MP, Kodde IF, Aster A, Bleys RL, Eygendaal D. Clinical relevance of distal biceps insertional and footprint anatomy. Knee Surg Sports Traumatol Arthrosc 2016;24:23007.

9. Champlin J, Porrino J, Dahiya N, Taljanovic M. A visualization of the distal biceps tendon. PM R 2017;9:210-5.

10. Doomernik DE, Kruse RR, Reijnen MM, Kozicz TL, Kooloos JG. A comparative study of vascular injection fluids in fresh-fro- 
zen and embalmed human cadaver forearms. J Anat 2016;229: 582-90.

11. Chang KV, Wu WT, Özçakar L. An uncommon cause of anterior elbow pain: diagnosis and injection for bicipitoradial bursitis using ultrasonography. Kaohsiung J Med Sci 2017;33:212-3.
12. Aly AR, Rajasekaran S, Ashworth N. Ultrasound-guided shoulder girdle injections are more accurate and more effective than landmark-guided injections: a systematic review and meta-analysis. Br J Sports Med 2015;49:1042-9. 